\title{
Complexity Management and System Dynamics Thinking
}

\author{
Stefan N. Grösser
}

\begin{abstract}
With the dawn of the internet, mobile technology, cloud computing etc. our socio-technical environment has become ever more intertwined and hyper-complex. The field of complexity management tries to devise methods and methodologies to cope with the challenges arising from complexity. This chapter provides a brief overview of the field of complexity management. More specifically, it defines in detail the terms complexity and dynamic complexity. Dynamic complexity is most relevant for high impact decisions and I examine two methods First, causal context modelling (CCM). This is an integrative, qualitative, transdisciplinary approach which creates a qualitative description of a system including key variable interdependencies and system boundaries. The second methodology I explore is system dynamics (SD). Here I provide examples from a project carried out within the Use-it-Wisely project which helped the companies involved understand and deal with the dynamic problems facing them.
\end{abstract}

Keywords Systems thinking - Causal context model - Context analysis • Qualitative method - Simulation method - Quantitative method - System dynamics - Mixed-methods • Integrative design - Complexity management - Dynamic complexity

\section{Introduction}

Leonardo Da Vinci said "simplicity is the ultimate sophistication" (Gaddis 1955; Granat 2003). Most managers would agree. Nobody would deny that the world has become more complex during the past decades due to technological change and globalization. With digitization, the interconnectivity between people and things has rapidly increased. Dense networks now define our technical, social, and

\footnotetext{
S.N. Grösser ( $\bowtie)$

Institute for Corporate Development, Bern University

of Applied Sciences, Bern, Switzerland

e-mail: stefan.groesser@bfh.ch 
particularly, business environments. The idea of applying complexity science to management was first discussed in the 1990s (Straub 2013). Popular literature propagated the ideas of complexity theory - in particular, the notion of the "butterfly effect" by which a small event in a remote part of the world could trigger a chain of events that would add up to a disruptive change in the whole system. Managers' eyes were opened to the reality that organizations are not just complicated but complex.

This growing complexity is why many management thinkers have been urging businesses to embrace complexity to become, in effect, system thinkers rather than reductionists. However, Straub (2013) states that complexity is not something managers need to embrace, merely something executives need to accept and manage. In fact, complex issues are often made worse by organizations themselves, especially by the approaches they adopt to deal with these issues (Isanda 2014). Managers and other business leaders seem to be vaguely aware of complexity's existence, and those that know of its existence do not know how best to deal with it - usually resorting to wishing it away or using models that give simplistic solutions that cannot be applied in turbulent and complex environments.

If you ask managers for the major business challenges within the next ten years, you will get the answer "complexity" quite frequently. It is a reoccurring theme in annual reports, analyst calls, and public speeches (Satell 2013). Failing to manage complexity causes high transition and overhead costs as well as frictional losses, inefficiencies, and difficulties in overall strategic orientation or incomprehensibility of the value chain. In particular, the challenge of managing high value assets has become ever more complex (see the challenges in chapter "The Challenge" in this book). It is therefore all the more important that decisions makers develop a deep understanding of complexity.

In this chapter, I provide a brief background on complexity and tools for its management. I define different types of complexities and then focus on dynamic complexity. Thereafter, I introduce causal context modelling (CMM) a specific method to structure messy problems. Then, I introduce the simulation methodology of system dynamics (SD). Both methods are highly useful when addressing the challenges resulting from the maintenance and upgrading of high-investment, industrial product-service systems (IPSS).

\section{Background on Complexity and Tools for Its Management}

Complex systems can be found anywhere multiple actors interact, are subject to feedback dynamics, and are influenced by time delays between cause and effect (Sterman 1994, 2002; Groesser 2014). Section 2 details six systems approaches that can help to understand and manage complex systems. These are soft system modelling (SSM), viable system model, mental models of dynamic systems, and 
group model building. Additionally in Sects. 3 and 4, I detail the methods of CMM and SD. But first, let us take a look into the underpinnings of complexity theory.

\subsection{Selected Background on Complexity}

The field of complexity theory or complexity science is vast and I do not intend to cover it comprehensively in this chapter. Rather, I briefly introduce complex adaptive systems (CAS) because they can be considered a theoretical background to many methods developed in the field of complexity management. More comprehensive overviews are available (Anderson 1999; Lewin 1999; Phelan 2001; Schwaninger 2009a, b).

"Adaptive social systems are composed of interacting, thoughtful (but perhaps not brilliant) agents. [...] What it takes to move from an adaptive system to a complex adaptive system is an open question and one that can engender endless debate. At the most basic level, the field of complex systems challenges the notion that by perfectly understanding the behaviour of each component part of a system we will then understand the system as a whole" (Miller and Page 2007: 3). Miller and Page refer to the difficulty of including aspects of complexity in a definition such as this. Simon understands CAS as "a large number of parts that have many interactions" (Simon 1997: 230). This definition corresponds with Gell-Mann (1995) who speaks of a CAS as an information processing system that "acquires information about its environment and its own interaction with that environment, identifying regularities in that information, condensing those regularities into a kind of 'schema' or model, and acting in the real world on the basis of that schema. In each case, there are various competing schemata, and the results of the action in the real world feedback to influence competition among those schemata" (Gell-Mann 1995: 117).

As Levy (1994) states, CAS can be found in a number of fields, including ecology, medicine, international relations and economics. In each case there are nonlinear and network feedback systems that handle information in a similar way. Gell-Mann (1995), Stacey (1995), Beinhocker (1997) and Pascale (1999) assert that the behaviour of CAS is at the root of the science of complexity. An illustration is provided by Bonabeau and Meyer (2001) who cite the example of ant colonies. In these colonies, interacting ants (agents) in an open-system are guided by simple rules. On an individual level, the behaviour of the ants seems to be random and unpredictable. However, on the macro-level, the collective behaviour that emerges out of the interactions between the ants exhibits a distinct pattern, resulting in a nonlinear growth of efficiency in the system - the ants' behaviour is characterized by flexibility, robustness and self-organization (Bonabeau and Meyer 2001). A similar example is provided by Kupers (2000) who observes that a group of door-to-door sales persons use random feedback loops to exchange information with each other on how to increase sales (i.e. how to increase the efficiency of the system). These feedback loops and exchanges of information lead to nonlinear and jumpy growth in sales (i.e. nonlinear increases in the system's efficiency). Thus, small causes of 
change can possibly have enormous effects on the outcome (the butterfly effect), through the non-linear amplification from feedback loops. Even a simple feedback system may result in (deterministic) chaos with an unpredictable outcome (Holbrook 2003). Anderson et al. (1999) suggests four elements that characterize [CAS] models that have particularly interesting implications for organizational theorists.

- Agents with schemata: Anderson's first element entails the idea that an organization's higher-level outcomes are produced by a system of agents at a lower level of aggregation such as individuals, groups or coalitions of groups. The agents act according to a schema, i.e., a cognitive structure that determines what action the agent takes at time $t$, given its perception of the environment at time $t$ (or at an earlier time, if theoretical considerations suggest applying a delay). The schemata are often modelled as a set of rules, but they can also be represented by a neural network that consists of a set of connected nodes where a signal from one node leads to a specific activation of the other. This understanding seems to be similar to Gell-Mann's (1995) depiction of CAS processes.

- Self-organizing networks sustained by importing energy: The second key element characterizing CAS is seen in the self-organization in such systems, where pattern and regularity emerge without the intervention of a central controller. There are three important notions behind the concept of self-organization: First, self-organization is the natural result of nonlinear interaction between simple agents. Nonlinear interaction in this context refers to self-reinforcing feedback cycles that can lead to self-amplifying behaviours. One condition for the existence of self-reinforcing feedback cycles is that interaction takes place between a large numbers of components. However, there is niether a lower boundary of interactions for self-organization nor also an upper one. Second, if interaction takes place between too many organizational actors, self-organization does not lead to pattern formation. In real human systems, however, agents only act on information available in their immediate environments: from those few agents connected to them in a feedback loop. And third, self-organization only occurs in open systems such as human organizations when energy is imported from the outside. The pattern, or dissipative structure, can only be sustained when the members contribute energy to make, break or maintain their ties to others.

- Coevolution to the edge of chaos: The third element is represented in the model of a "fitness landscape". This is a metaphorical map of a mountain region, where agents act to increase their payoff or fitness, i.e., their altitude (Epstein and Axtell 1996). The landscape continually shifts because it is affected by the agent's actions. Also, the individual fitness functions of agents affect each other as each individual trajectory is adjusted according to the successes of its neighbours (Eberhart et al. 2001). In this sense, agents usually co-evolve at a local level. The co-evolvement leads to a dynamic equilibrium in the system which might be thought of as teetering on the edge of chaos (Beinhocker 1997). Small changes in the actions or the behaviour of agents can have small, medium, 
or large impacts on the system as a whole. If the system is in chaos, i.e., beyond the edge, then small changes in behaviour lead to widely different fitness levels, systems can reach extraordinary fitness peaks, but cannot remain on them. The slightest change in behaviour will send the system tumbling off its peak, perhaps plunging into a region of very low fitness. On the other hand, if small changes in behaviour lead only to small cascades of co-evolutionary change, the system's performance can never improve much.

- Recombination and system evolution: The fourth element is that every aspect of a complex adaptive system - agents, their schemata, the nature and strength of connections between them, and their fitness functions can change over time. That is, new agents and new schemata can be introduced to the system, and ties between agents emerge, break and are sometimes re-established. To model an organization, it is important to consider that the relationship between variables (or agents) is not fixed (as in traditional causal models).

\subsection{Definition of Complexity}

After this brief examination of the theoretical background of complexity research, let us move our attention to practical side of things and concentrate on the management of complexity and the tools used. Research on the management of complexity and complex systems is particularly considered in technological and natural sciences (Bleicher 2004; Kastl and Schmid 2008). Since the 1960s, the social sciences have repeatedly analysed the steering of complex systems within the field of management theory (Malik 2008). In both the realms of scientific research and society in general, there is still no uniform understanding and consensus on the concept of complexity. Equally, it is not possible to find a consistent and generally-accepted definition of complexity. Depending on the pursued research goal or which method is applied, definitions and interpretations differ substantially (Kirchhof 2003; Scherf 2003; Rall and Dallhöfer 2004; Kersten et al. 2012).

Ulrich and Fluri (1992) define complexity in terms of situations that contain a high diversity of influencing factors and numerous mutual interdependencies which prevent structural decision-making. However, complexity must be distinguished from complicated systems. The difference between complex and complicated issues is determined by the degree of predominant uncertainty. Results in complicated systems are predictable due to the linear behaviour of their variables (Simon 1962).

Casti (1994) determines complexity by means of specific criteria. Complex systems do not possess a central control centre but rather consist of numerous, communicating units. Furthermore, feedback relationships between variables and delayed cause-and-effect are present within the complex system. The most prominent feature, however, is the characteristic of irreducibility, i.e., the system as a whole is greater than the sum of its parts and exhibits dynamic, emergent patterns. 
Klabunde (2003) describes complexity through the characteristics of variety, connectivity and dynamics. Variety concerns the number and type of elements in a system, whereas connectivity deals with the number and type of the relationships between the variables. The characteristic "dynamic" captures the uncertainty and unpredictability of complex systems (Denk and Pfneissl 2009; Schoeneberg 2010).

Groesser $(2015 \mathrm{a}, \mathrm{b}, \mathrm{c})$ and others create the distinction between simple, complicated, complex, and hyper-complex (i.e., chaotic) systems. These four types of systems can be divided into a four-field matrix representation (Fig. 1), which is spanned by the system characteristics "variety/diversity" (y-axis) and the "variability/momentum" (x-axis).

- A simple system is characterized by a low number of components, which are not subject to variability themselves. An example is a simple process of predetermined steps in a production chain. In a simple system it is possible to estimate the progression of effects since they are stable over time.

- A complicated system comprises many combinatorial possibilities that arise due to the large number of components in the system and the array of possible combination between them. This complexity is also referred to as "detail complexity" or "combinatorial complexity". Everyday decisions are complex if a large number of different elements have to be considered for decision-making. One example is an antique church bell. The mechanical system is highly complicated. However, in principle the stages of each element can be known, moreover, how they interact is definable and thus limited. Moreover, the progression of these interactions is relatively stable.

- The defining characteristics of a complex system are its high variation in the elements and their relationships in a system, i.e., their variability, momentum, or behaviour. This leads to the concept known as "dynamic complexity" (Richardson and Pugh 1981; Senge 1990) which is the ability of a system to be able to develop into different states over time. For a complex system, it is still possible to understand the interrelations and development ex-post. The amount

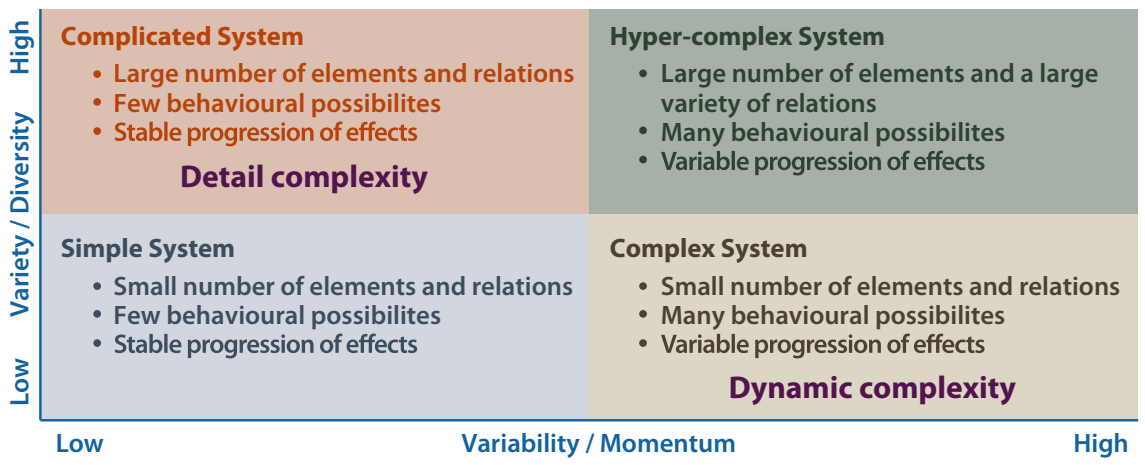

Fig. 1 System types from simple, to complicated, to complex (Ulrich and Probst 1991; Groesser $2015 \mathrm{a}, \mathrm{b}, \mathrm{c})$ 
of variables and interconnections is moderate; the amount of interconnections can be large.

- A hyper-complex (chaotic) system comprises of a large amount of different variables which have a large number of interconnections. Understanding the development of the system over time is not feasible due to the many interacting and changing variables. From a management science perspective, it is only of little use to try to detail the inner workings of such hyper-complex systems since they cannot be inspected and clearly analysed or only with large estimation errors.

Table 1 details the definition of simple, complicated and complex systems based on the system's characteristics: number of elements, similarity of the elements, variability of the elements over time, the number of relationships and the connectedness of the relations. The characteristics of hyper-complex systems are not detailed here. They can be derived from the characteristics of complicated and complex systems.

Complex systems, as defined in Fig. 1 and Table 1, can exhibit dynamic complexity. Dynamic complexity is the label given to a system whose characteristics do not follow direct and simple (i.e., linear) cause-effect relationships. Dynamic complexity results from temporal interactions and interrelationships of system elements. It is considered to be caused specifically by delays, feedback, accumulations and nonlinearities. Dynamically complex situations are essentially not transparent for a decision-maker. He or she has no means of intuitively detecting the connection of circular causality and way of modelling and predicting them exactly. The decision-maker must expect surprises, side effects and unintended effects of decisions in different parts of the system.

Criteria for dynamic complexity: A system is dynamically complex if the following, but not necessarily all, criteria are met:

Table 1 Comparison of simple, complicated, and complex systems

\begin{tabular}{l|l|l|l}
\hline Characteristics & Simple systems & $\begin{array}{l}\text { Complicated } \\
\text { systems }\end{array}$ & Complex systems \\
\hline Number of elements & Few & Large & Moderate \\
\hline $\begin{array}{l}\text { Similarity of the } \\
\text { elements }\end{array}$ & $\begin{array}{l}\text { Identical in all } \\
\text { characteristics }\end{array}$ & $\begin{array}{l}\text { Partly or entirely } \\
\text { different }\end{array}$ & $\begin{array}{l}\text { Partly or entirely } \\
\text { different }\end{array}$ \\
\hline $\begin{array}{l}\text { Variability of elements } \\
\text { over time }\end{array}$ & No & No & Yes \\
\hline Number of relationships & Few & Moderate/large & Large \\
\hline $\begin{array}{l}\text { Connectedness of } \\
\text { relations }\end{array}$ & Few & Moderate/large & Large \\
\hline Example & Pendulum & Car, engine & Business ecosystem \\
\hline
\end{tabular}


1. Dynamic: The system develops or changes over time. What seems to be fixed, varies over a longer time horizon.

2. Close connection of the system elements: The system elements or agents in the system interact strongly with each other.

3. Feedback: Systems are controlled by feedback. This coupling between system elements actions and events can react upon themselves.

4. Non-linearity: Non-linearity exists when at least one element in the system interacts with another in a non-linear way. Non-linearity is graphically expressed as a curved, e.g., exponential or quadratic line. In particular, "non-linear" means that an effect is seldom proportional to its cause.

5. Past dependent: Past dependent means that the decisions, which must be made by an agent, depend on the decisions already taken in the past. Structure in any system is the product of past actions (interactions).

6. Self-organizing: The dynamics of the system are formed by self-organization and spontaneous consequence of its internal structure.

7. Adaptive: Adaptive means that a system itself changes as a result of experience. Thus, the skills and decision rules of agents change in a complex system over time.

8. Counterintuitive: Decision-makers cannot capture causes and their effects only relying on intuition. The behaviour of the system is often against, i.e., counter, the behaviour the decision-makers expect. This is because causal relationships are often not sufficiently understood since it is often neglected that causes may have different intended and unintended effects.

9. Intervention resistant: The complexity of the system, in which an agent is embedded, overwhelms his or her ability to understand the system. Consequently, implemented solutions often fail in a complex system or even aggravate the situation. Interventions do not produce obvious (expected) effects or even lead to unintended consequences.

10. Temporal balancing decisions (trade-offs): time delays result in a system in which the long-term effects of an intervention are often different from the short-term effects.

\subsection{Short Overview of Some Tools for Managing Complexity}

After introducing the foundations of different types of complexity, I will now briefly look at several tools from the field of complexity and systems theory which have been developed to cope with the ever growing situations of complexity. We will not concern ourselves with the methods of CCM and SD in this section since they are introduced later in detail in dedicated subchapters. 


\subsubsection{Soft System Modelling}

SSM incorporates an interpretive perspective of social settings (Lane and Oliva 1998). With a focus on action-research, SSM practitioners do not attempt to describe the real world, rather they use several models, i.e., ideal types, to explain a problem from different perspectives. The ultimate goal is to gain insights and changes by comparing ideal types with the real world problem. The models themselves are represented by a mapping technique which results in "rich pictures" of the problematic situation (Fig. 2).

\subsubsection{Cybernetic Models}

The cybernetic view of socio-technical systems is suitable for diagnosing and de-signing organizations. Stafford Beer's viable system model (Beer 1979, 1981) is one of the most wide-ranging theories in this discipline (Fig. 3). Despite its applicability to any human or social system, it has primarily been used to describe the viability of organizations. An underlying proposition is that an organization is only viable if it has a set of management functions and interrelationships as specified by the theory (Schwaninger and Ríos 2008). Differences between the

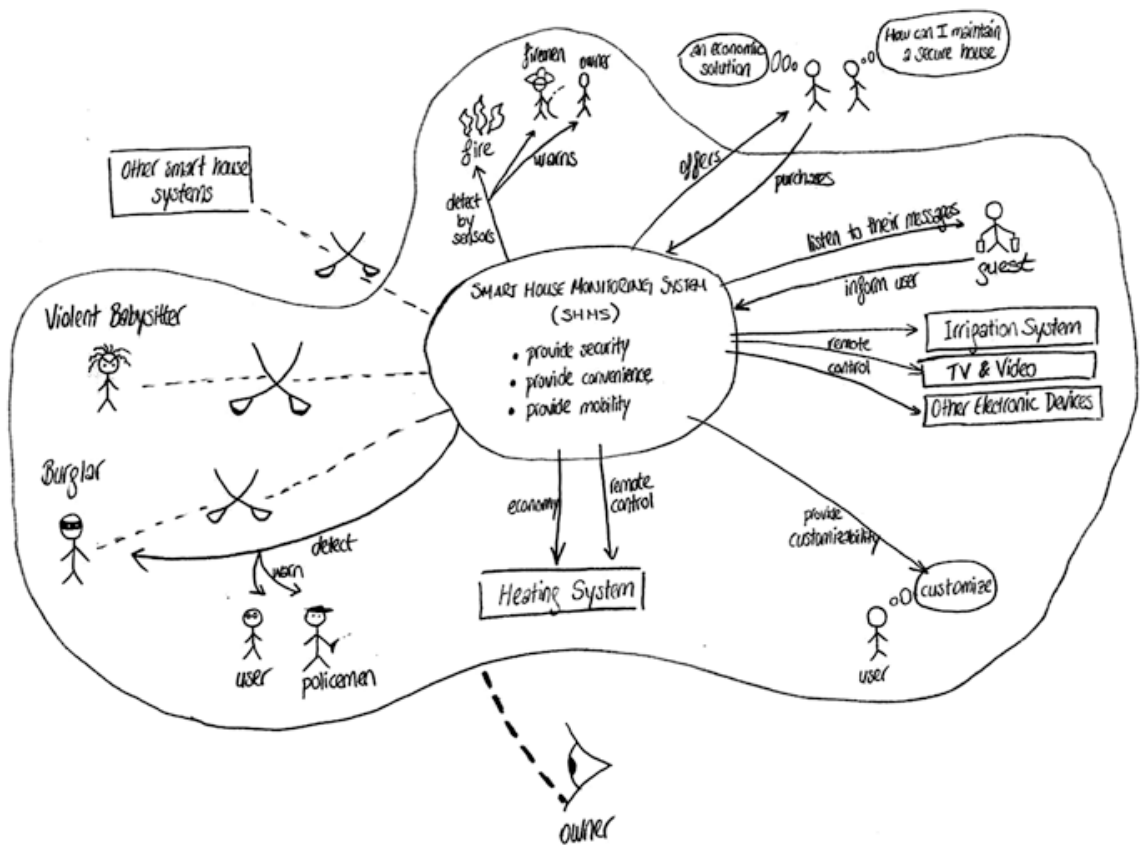

Rich Picture

Fig. 2 Rich picture as used in the SSM (Checkland 2001) 


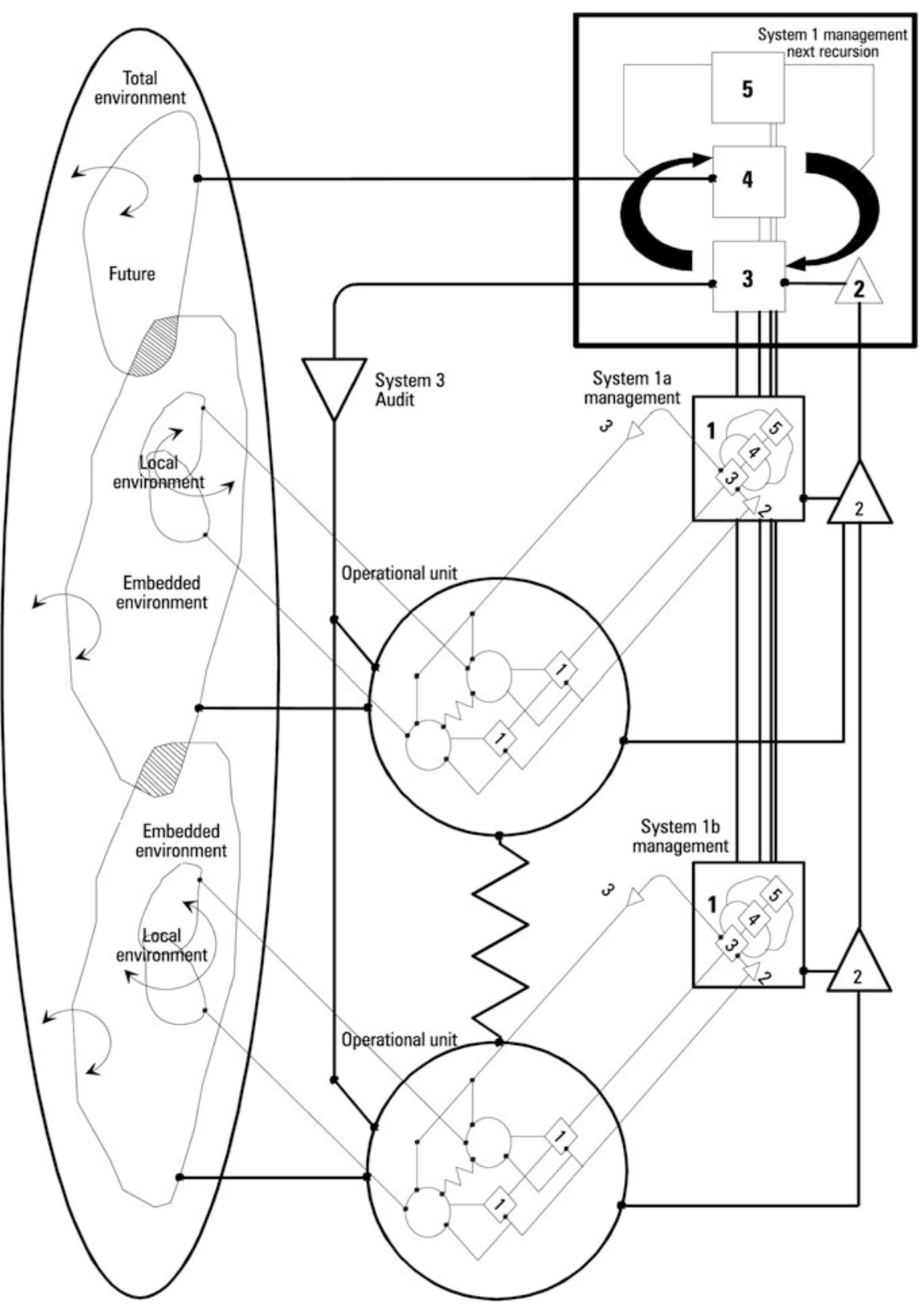

Fig. 3 Viable system model (Beer 1981)

elements and links of the real system and the elements and links as proposed by the Viable System Model result in a possible threat to the viability of the organization. 


\subsubsection{Mental Models of Dynamic System}

An anthropocentric approach focussing on humans' ability to reason is the concept behind mental models. It has been shown that humans' ability to perform in dynamic complex settings is limited and biased. Therefore, improved mental models which account for accumulation processes, time delays, and feedback loops are required (Groesser and Schaffernicht 2012). The mental model approach to dynamic systems has been developed to elicit managerial cognitions about dynamic situations to represent these cognitions, and to analyse the mental models with the objective of improving decision-making. The most recent methods of elicitation and comparison can be found in (Schaffernicht and Groesser 2011; Groesser and Schaffernicht 2012; Schaffernicht and Groesser 2014).

\subsubsection{Group Model Building}

Group modelling is a process which is expected to adapt mental models and foster the implementation of decisions (Rouwette et al. 2011). This process is based on involving different actors, e.g., clients and experts, who provide particular knowledge about contents or techniques (Vennix 1996). The goals of group model building are versatile. By means of group model building, the individual and group mental models can be aligned. This improves the clarity and efficiency between different system actors.

\section{Deep-Dive I: Causal Context Models}

\subsection{Purpose of Causal Context Models}

This section provides details about CMM. A CCM is a qualitative word-and-arrow diagram, i.e., a graphical representation that details the cause-and-effect relationships between variables in a system. A CCM follows, in principle, the method of a causal (loop) diagram (Richardson and Pugh 1981; Sterman 2000; Lane 2008; Groesser 2016). It emphasizes the interdisciplinary interaction between technological, social, legal, and natural spheres when high-value IPSS, and other systems, are managed (see chapter "The Challenge" of this book for the challenges of upgrading and managing IPSS).

The objective of a CCM is to explain the behaviour of technical- and business-level variables which are key to an organization's objectives. In doing so, a good model will reveal the network of influences that impinge on those variables. Before one can start to use CCMs some prerequisites are helpful: (1) openness to a new qualitative method, (2) thinking in variables and how they are interconnected, (3) a mind-set open to crossing disciplinary boundaries to connect different fields of 
thought (e.g., engineering, informatics, and business). A CCM helps those involved to evaluate the impact of changes to their business-level objectives and compare various these scenarios using behaviour over time charts. To do this, the user imagines changing the value of a relevant variable in the model and then traces the consequences through the model to see if the desired and expected outcomes are achieved. This is done in a qualitative, imaginative way of reasoning.

\subsection{Elements of a Causal Context Model}

A CMM consists of variables and directional causal links that have one of two possible polarities. A link marked positive (+) indicates a positive causal relation and a link marked negative $(-)$ indicates a negative causal relation.

- A positive causal link (+) means the two variables, which are connected by this causal link, change in the same direction. In other words, if the initial variable decreases, the other variable also decreases. Similarly, if the variable, in which the link starts, increases, the other variable increases as well.

- A negative causal link (-) means the two variables, which are connected by this causal link, change in opposite directions. In other words, if the initial variable increases, the other variable decreases and vice versa.

It is common for CCM to have closed chains of causal links known as feedback loops (Sterman 2000). A feedback loop can either be reinforcing or balancing.

- A reinforcing feedback loop $(\mathrm{R})$ is a closed causal chain in which the effect of a variation in any variable propagates through the loop and returns to the variable thus reinforcing the initial deviation. In other words, if a variable increases in a reinforcing loop the effect through the cycle will return an increase to the same variable and vice versa. An example of a reinforcing loop is the word of mouth dynamics. In reaction to any questionable statement or activity of an organization, social media users can create huge waves of outrage within just a few hours. These so-called online firestorms pose new challenges for marketing communications - reinforcing feedback dynamics.

- A balancing feedback loop (B) is the closed causal chain in which the effect of a variation in any variable propagates through the loop and returns to the variable a deviation opposite to the initial one. In other words, if a variable increases in a balancing loop the effect through the cycle will return a decrease to the same variable and vice versa. An example of a balancing loop is the actions executed by managers to prepare and avoid online firestorms, as described above. The company's capabilities are built-up until the management is satisfied. Then, no further investments are executed. A balancing feedback loop leads to goal-seeking dynamics of the respective system. 
A CCM explicates the assumptions and helps thereby to reveal how things are connected to each other within a system. The example in Fig. 4 shows an example of a CCM developed for an organization taking part in the UIW-project. The figure should provide an indication of how a CCM looks; I do not intend to detail or explain the CCM here. It shows the technical-level (e.g., total construction time or number of vague regulations) and business-level objectives (e.g., return on investment), scenario variables (e.g., number of future regulations issued or effectiveness of future regulations), and feedback loops (B1 to B4).

In addition to the causal, structural model, a CCM requires that at least one behaviour over time chart (also known as a BOT or a time chart) of an important variable is developed. The variable has to be an element of the CCM (see Fig. 5).

\subsection{Causal Context Model Development}

CCMs are developed to create comprehensive causal maps, i.e., models that include different perspectives on a challenge that needs to be managed. For instance, all companies that participated in the UIW-project (see Part III of this book) established CCMs that show the relationships between technical-level objectives and business-level objectives. The CCM supports the definition of the problem to be addressed as well as helping elaborate possible solutions. The generic process of CCM development follows six steps:

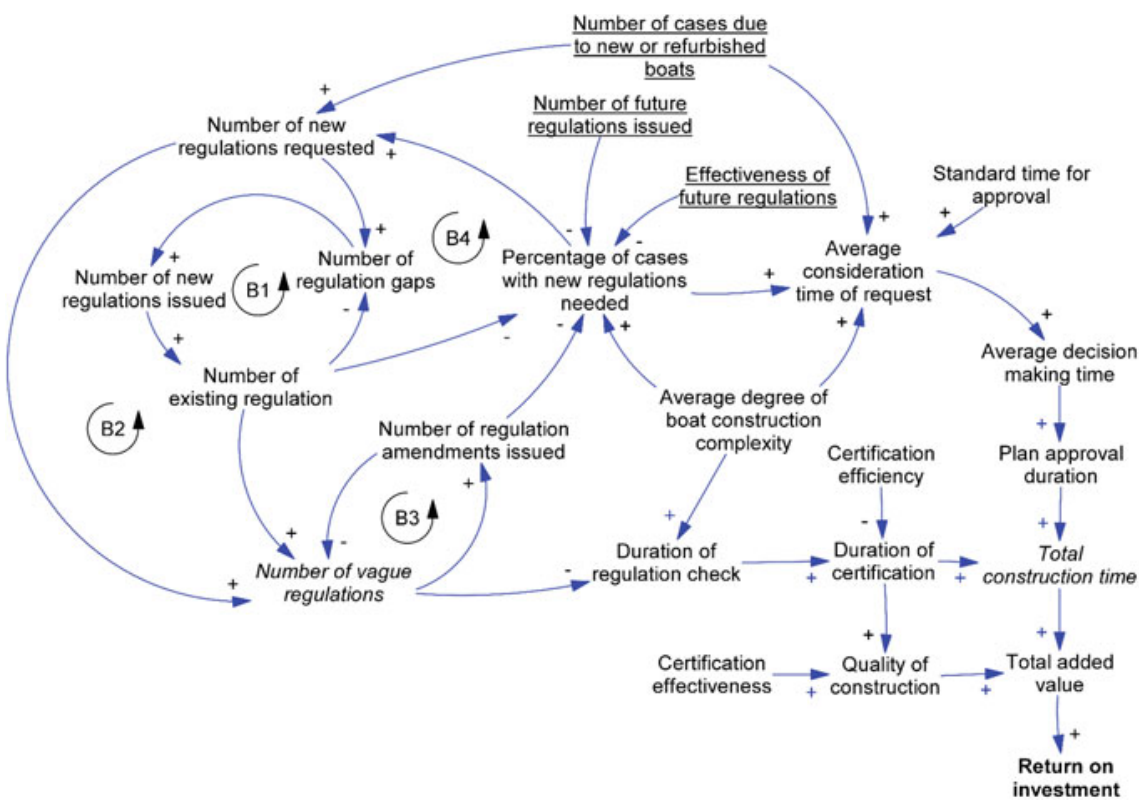

Fig. 4 Example of a causal context model 


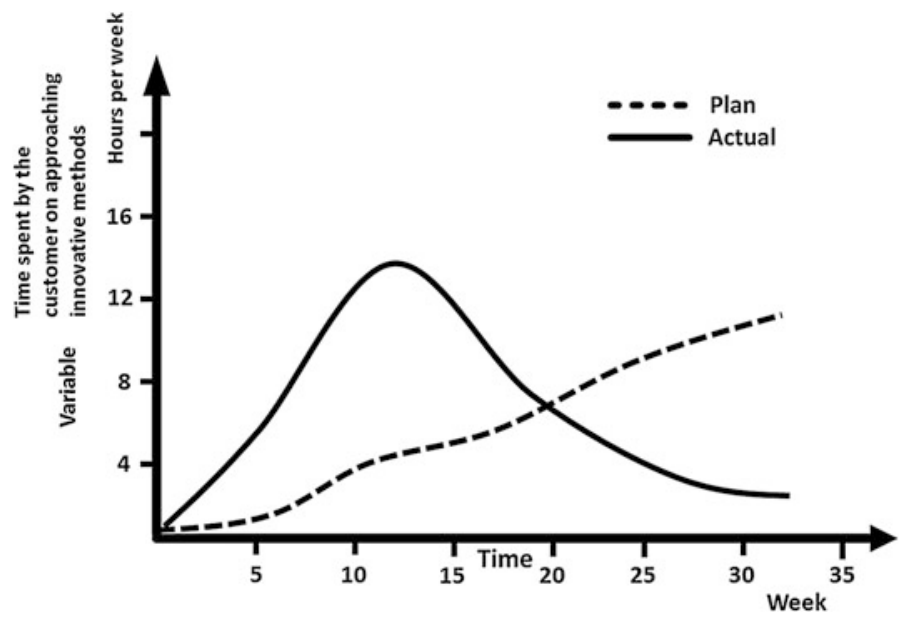

Fig. 5 Example of a behaviour over time (BOT) chart

1. Define the reference behaviour in technical-level objectives by means of behaviour over time charts: the reference behaviour is the over time development of an important technical variable, e.g., availability of relevant information to project team. This variable shows problematic behaviour, e.g., that the level of relevant information the team has access to does not conform to the intended level. One, or ideally, several such reference modes in technical-level variables should be defined. The tutorial https://www.youtube.com/watch?v= ktKGrDds3No provides additional information about step 1.

2. Define the reference behaviour in business-level objectives by means of behaviour over time graphs: Then, perform step 1 now for business-level objectives. Develop behaviour over time charts for variables that show business-level objectives. Examples of such variables are market share, revenues, customer satisfaction, or throughput time. The business-level objectives are then: to have a higher market share, increased revenues, higher customer satisfaction, or lower throughput time (see the charts in Fig. 4).

3. Develop the causal model: in order to develop a causal model the next step is to connect the technical-level and business-level variables by means of causal links. One will certainly have to include new variables about relevant aspects of the system being modelled to create the causal paths between the different variables. Only include variables and causal links that exist in the system. All the relevant variables have to be included in the final model so as to sufficiently explain the behaviour of the objective variables in steps 1 and 2 .

4. Define scenario variables: After the causal model is completed, ensure that the model includes important scenario variables. A scenario is a description of possible external developments in the future. A scenario variable, e.g., requirements for energy efficiency, operationalizes these possible developments by embedding these clearly in the causal model. Scenario variables assume 
different values, e.g., legal requirements for energy efficiency might be change. The CCM helps the user to think about the following developments:

- If the scenario variable $X$ increases (or decreases respectively), how will the technical-level objectives develop?

- If the scenario variable $X$ increases (or decreases respectively), how will the business-level objectives develop?

5. Define policy variables: A policy is a set of basic principles and associated guidelines, formulated and enforced by the governing body of an organization, e.g., a decision maker, to direct and limit his or her actions in pursuit of long-term goals. In other words, a policy is a decision rule that defines how available information is used for decision making. One example is a hiring policy: it guides the each (monthly, annual etc.) decision about how many people should be hired. Polices are operationalized by policy variables which are under the control of the decision maker. This step should ensure that the relevant polices, i.e., measures a decision maker can influence, to achieve the technical-level and business-level objectives are included in the CCM.

6. Continuously validate the model being created: Validation activities occurs continuously during the model creation process. For more information on this, see Groesser and Schwaninger (2012) who go through the modelling process (both qualitative and quantitative) in more detail (see also Barlas 1996; Forrester and Senge 1980; Schwaninger and Groesser 2009). The modeller has to ensure that the resulting CCM only features variables and causal links with polarities. Other concepts are not used in CCMs.

The process of developing a CCM is a learning process for the participating organization. For each iteration, the CCMs are expanded with new variables, causal relationships, scenario and policy variables. Discussions about different meanings of specific variables as well as different causal relationships foster understanding between participants and also nurture learning about the context in which the decisions on the technical and business-level are made.

CCMs offer several benefits: first, different perspectives, e.g., economic, technical, and social aspects, can be integrated into one holistic model; second, CCMs are statements about causes and consequences. Such a causal model becomes a tool with which concrete actions to overcome challenges can be found. A CCM is, however, a qualitative model. The next step of analysis would be do develop a quantitative simulation model. The advantage of such a simulation model is that the participants cannot only identify positive and negative effects, but also by how much the changes can impact their technical-level objectives and their business-level objectives. Furthermore, the rigor a simulation model requires leads to a more intense and in-depth thought process regarding the different causalities and values as well as the expansion of the model boundary. This is what I address next. 


\section{Deep-Dive II: System Dynamics Simulation Modelling}

\subsection{Purpose of System Dynamics Modelling}

System Dynamics (SD) is one of the most popular, widespread and validated simulation (computational) methodology and cannot be overlooked when discussing decision making tools and complexity management. In this Sect. 1 will briefly address SD simulation methodology and address in more detail how it can be useful when managing real world complexity. The more curious reader will benefit greatly from the references supplied here.

The basic idea of SD is to capture the underlying characteristics of complex dynamic systems to understand them better and foster desirable developments (Schwaninger and Ríos 2008; Schwaninger and Groesser 2008). To capture all these characteristics SD-models must represent nonlinearities, long-term patterns and the internal structure of a system. This is technically achieved by mapping the system's stock- and-flow structure. Jay Forrester, the founder of SD, devised the means of modelling any dynamic situation by means of stocks and flows. The process of building an SD model is a continuous learning process consisting of formulating hypotheses, testing, and revising formal and mental models. SD captures essential characteristics of management reality, for instance, nonlinear behaviours, accumulations, delays, and information feedback, which are not systematically taken into account by existing methods (Sterman 2000; Schöneborn 2003; Morecroft 2007; Warren 2008). A computational modelling approach is most helpful in providing insights about the type and magnitude of interaction in high value asset system and allows an integrated evaluation and thereby complements the existing methods in the analysis of such systems.

\subsection{System Dynamics Modelling Process}

When creating a System Dynamics model, a six step modelling development process is used: (1) selection of the dynamic problem, (2) conceptualization, (3) formulation, (4) scenario and policy analysis, (5) selection of policies and implementation planning, and (6) implementation (Fig. 6).

\subsubsection{Step 1: Selection of the Dynamic Problem}

The first step of the modelling process is to identify the issue and the relevant stakeholders. This enables modellers to identify from whom to draw expertise when developing the model as well as from where to collect data in the latter stages of the process. The development of a model will require the collaboration between the 


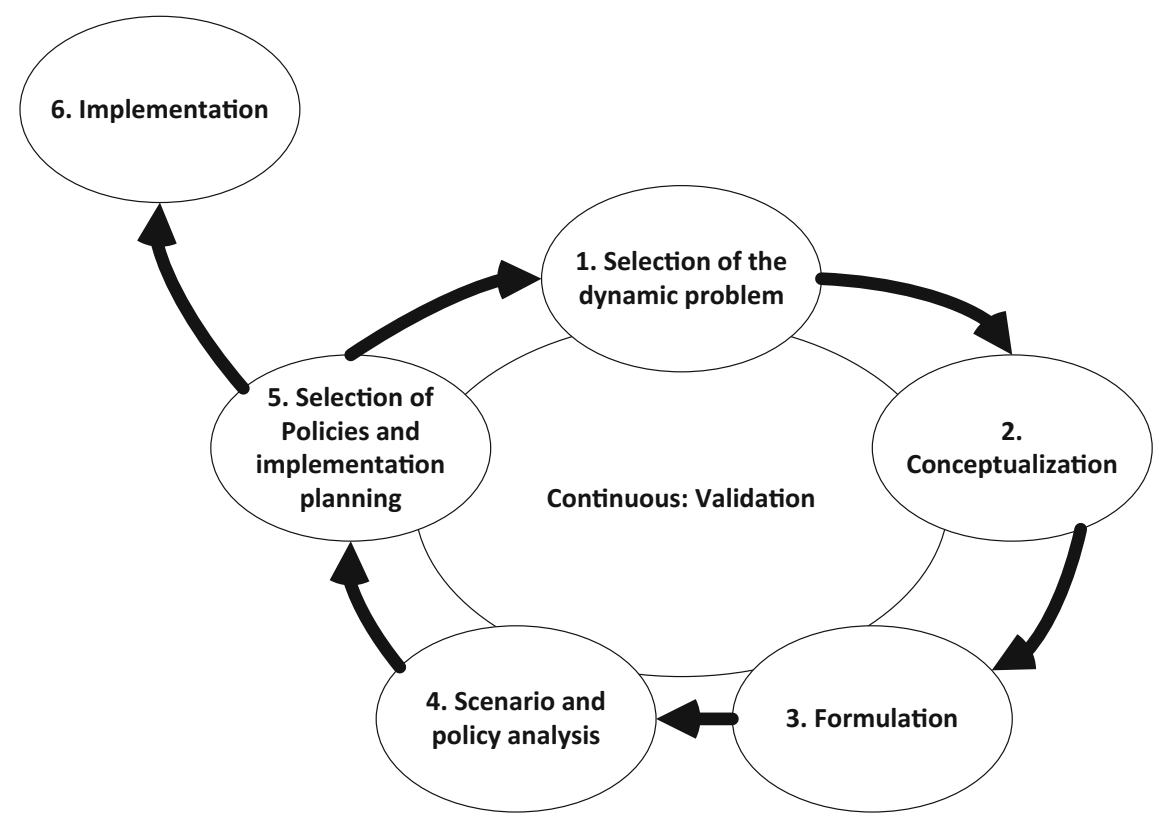

Fig. 6 Process for developing system dynamics simulation models

"problem owners" and modellers to produce a high-quality model. Initially, the problem owners provide the essential information about the issue at hand and are then involved in every iterative modelling step. It is essential that the problem owners comprehend the basic functioning of the model and continuously validate the output of the model. After getting an initial feel for the environment of the model, the modeller formulates a dynamic hypothesis of the problem. This dynamic hypothesis is founded on the information provided by the owners as well any current theories which help to explain the problem.

\subsubsection{Step 2: Conceptualization}

After identifying and selecting the dynamic problem, the task is to decide upon a provisional list of variables and a suitable time horizon for the model, from which the necessary behaviour over time graphs (BOTs) can be generated. All this is done based on data or the expectations of the relevant stakeholders. This stage should not be considered as final since the modelling process is iterative and the modeller, together with the stakeholders and problem owner, will revise these decisions repeatedly until the model is completed. This iteration also includes repeated feedback from the stakeholders to gain a better understanding of the model. 


\subsubsection{Step 3: Formulation}

Based on the available data resources (e.g., a previously generated Causal Context Model (CCM)) and the identified problem, the modeller now defines what kind of model is to be created. For some dynamic problems a qualitative model might suffice, meaning the model can start out as Causal Loop Diagram (CLD). If a quantified model is the goal, then a Stock- and Flow-Diagram (SFD) should be considered more suitable. In the case of a quantified model, after translating the variable list into a SFD, the modeller populates the variables with values to create a first iteration of the simulation model. Initially the values and functions added to the model can be guesses or estimates (or even guessimates!), as the modeller will revise them for every iterative step and continuously increase their precision. Also, continuously simulating the model will provide the modeller with insights for further model development. Step 3 also enables the modeller to continuously test their model BOTs by comparing it to the initially generated BOTs, by testing the robustness of the model and/or testing sensitivity.

\subsubsection{Step 4: Scenario and Policy Analysis}

Finally, when the modeller is satisfied that the model is of sufficient quality he or she can start analysing and evaluating policies and scenarios. Scenarios are analysed by changing exogenous variables to simulate different developments in the environment of the system. If for example the model depends on economic growth, the modeller can evaluate the impact and the sensitivity of the system to an economic slowdown or sudden increase in economic activity. The degree to which the system changes as a result of that external change reveals the model's sensitivity to that exogenous variable. This allows the practitioner to analyse the likelihood of any given situation to materialize under a certain set of external conditions. The model also allows the efficacy of different responses to external changes in the system to be tested. This gives the modeller the opportunity to select policies and responses to optimize the resilience of the system in the face of external shocks.

\subsubsection{Step 5: Selection of Policies and Planning of Implementation}

After agreeing on the most important scenario settings and most effective policies, the modeller applies these conditions to the model and discusses the results with the stakeholders. The stakeholders can then evaluate and define the most effective way to apply the policies in the system in question. With the insight gained from the discussion of the model, the stakeholders can then implement actions necessary to change the system in real life while already anticipating and validating whether the measures achieve the desired effect. 


\subsubsection{Step 6: Implementation}

Implementing the planned changes and measures is in the responsibility of the problem owner. Often it is helpful, when the simulation model and its results are demonstrated to the people who are affected by the changes and measures. It is especially productive to hold demonstration workshops during which the participants can experiment with the simulation model for themselves. These sessions will often throw new light on the problem and provide fresh impetus to make any necessary changes.

\subsection{Applying System Dynamics}

With regard to managing complexity, the following paragraphs describe five advantages of SD simulation methodology as well as explaining some of its disadvantages. First, any tool for decision-making has to satisfy several criteria to effectively deliver decision support. According to John D. C. Little (1970) these criteria are simplicity, robustness, ease of control, adaptiveness, completeness on important issues, and simplicity of communication. In close connection with the decision maker, a computational modelling process begins with a simple model structure and continuously improves in an evolutionary way using rapid prototyping. As a result, this process of elaboration and calibration creates a sufficient, robust and purpose-oriented model. Furthermore, the involved decision makers learn how to control the model during its execution. The unfolding model is permanently represented as a visual object to ensure transparent communication with the target audience (Black and Andersen 2012; Nistelrooij et al. 2015).

Second, the approach can improve a company's capabilities when analysing the interdependencies in their business models in the face of external changes in the environment. Since simulation approaches are capable of representing highly complex situations and handling them in a reasonably simple way, it becomes possible to address a higher degree of the dynamic complexity present in business reality (Groesser and Schwaninger 2012). As a direct consequence of structuring and linking knowledge about a business system, SD allows decision makers to take decisions which are based on integrative qualitative and quantitative analysis.

Third, risks can be identified through sensitivity analysis of the feedback dynamics in a simulation model. Risks are often identified in the following three areas: firstly, balancing feedback loops that limit a desired growth or decay; secondly, reinforcing feedback loops that lead to undesired growth or decay; and thirdly, external factors that exacerbate any of above two types of feedback loops. Analysis of feedback dynamics can make some systemic risks apparent, which otherwise might be too vague to attract notice. SD can be used to quantify risks which are attributed to be most relevant (Rodrigues and Bowers 1996).

Fourth, SD emphasizes a continuous perspective (Sterman 2000). This perspective strives to look beyond single events to see the dynamic patterns underlying 
them in the short-, as well as, long-term. Then, by identifying those patterns, simulations help to understand the causes of current issues and can support decision makers in tackling them. Moreover, applying computational modelling supports the validation of strategic initiatives and their effect on existing business models-just as engineers test new technologies or products extensively in a laboratory before their market launch. In particular, the ability to experiment with different scenarios and strategic initiatives in a computational environment has the potential to reduce erroneous management decisions and reveal overlooked factors and patterns that could become relevant in the future (Groesser 2015a, b, c).

And finally, by amalgamating computational methods with existing business modelling approaches SD provides an insightful, valid, relatively rapid, and inexpensive approach to business model analysis and design (Eden et al. 2000). Moreover, from a perspective of consistency, it is known that humans cannot deduce the behavioural consequences of a system with many interdependent elements (Miller 1956; Forrester 1961; Sterman et al. 2015). Computational modelling is one of the means, amongst others, of reducing the issue that qualitative models seem to be insufficient when systems are highly complex (Sterman 2000). Hence, it enables a deep and integrated understanding of a system through the quantitative exploration of systemic interdependencies.

Computational modelling of complex systems is a relatively innovative approach for top management decision makers. Some disadvantages of this method relate to the relative ease of linking variables together to quickly create large, highly complex models. Some users may, however, be overwhelmed by this complexity if they do not exercise a cautious approach to modelling (Groesser and Schwaninger 2012). The existence of user-friendly visual representations has, in some cases, been a disservice by offering the false impression that modelling is always simple and done quickly. In addition, inclusion of uncertain or only hypothesized feedback loops may create complex model behaviour that may be difficult to track, falsify, or validate. Moreover, the empirical evidence about the learning outcomes of computational modelling and its effectiveness is still inconclusive (Karakul and Qudrat-Ullah 2008; Sterman 2010; Qudrat-Ullah 2014). Consequently, it is not yet possible to state that businesses applying computational modelling systematically produce better results than those that do not use it and thus, the requirements of the strong market test are not yet met (Labro and Tuomela 2003). At the same time, this is a call for action to conduct more empirical research to prove (or disprove) the case for computational simulation methods.

\section{Conclusion}

This chapter introduced the reader to systemic methods which are highly beneficial in the analysis and management of complexity, especially in cases when managing high value assets. The chapter introduced two methods in more detail: the qualitative method, CCM, and the quantitative method, SD, methodology. The chapter 
explained both methods and provided the reasoning for their applications as well as discussing their potential benefits.

Acknowledgements I would like to thank Stefan Katz for his professional support during the development of cluster cases in the UIW-project. Also I want to thank Daniel Foord for his exceptional support with regard to the English in this chapter.

\section{References}

Anderson, P. (1999). Complexity theory and organization science. Organization Science, 10(3), 216-232.

Anderson, P., \& Meyer, A., et al. (1999). Introduction to the special issue: Applications of complexity theory to organization science. Organization Science, 10(3), 233-236.

Barlas, Y. (1996). Formal aspects of model validity and validation in system dynamics. System Dynamics Review, 12(3), 183-210.

Beer, S. (1979). The heart of the enterprise. Chichester: Wiley.

Beer, S. (1981). Brain of the firm. London: Penguin Press.

Beinhocker, E. D. (1997). Strategy at the edge of chaos. McKiney Quarterly, 1(24-39).

Black, L. J., \& Andersen, D. F. (2012). Using visual representations as boundary objects to resolve conflict in collaborative model-building approaches. Systems Research and Behavioral Science, 29(2), 194-208.

Bleicher, K. (2004). Das Konzept Integriertes Management. Visionen - Missionen - Programme. Frankfurt, Campus.

Bonabeau, E., \& Meyer, C. (2001). Swarm intelligence-A whole new way to think about business. Harvard Business Review, 79(5), 106-114.

Casti, J. L. (1994). Complexification, explaining a paradoxial world through the science of surprise. New York City: HarperCollins Publisher.

Checkland, P. (2001). Soft system methodology. In J. Rosenhead \& J. Mingers (Eds.), Rational analysis for a problematic world revisited: Problem structuring methods for complexity, uncertainty and conflict (2nd ed.). Chichester, New York, Weinheim, Brisbane, Singapore, Toronto: Willey.

Denk, R., \& Pfneissl, T. (2009). Komplexitätsmanagement. Wien: Linde.

Eberhart, R. C., \& Shi, Y., et al. (2001). Swarm intelligence. Morgan Kaufmann.

Eden, C., Williams, T., et al. (2000). The role of feedback dynamics in disruption and delay on the nature of disruption and delay (D\&D) in major projects. The Journal of the Operational Research Society, 51(3), 291-300.

Epstein, J. M., \& Axtell, R. (1996). Growing artificial societies: Social science from the bottom up. Cambridge, Washington D.C.: Brookings Institution Press, The MIT Press.

Forrester, J. W. (1961). Industrial dynamics. Cambridge: Productivity Press.

Forrester, J. W., \& Senge, P. M. (1980). Tests for building confidence in system dynamics models. In A. A. Legasto, J. W. Forrester, \& J. M. Lyneis (Eds.), System dynamics: TIMS studies in the management sciences (Vol. 14). Amsterdam, North-Holland.

Gaddis, W. (1955). The recognitions. San Diego: Hartcourt Brace \& Company.

Gell-Mann, M. (1995). The quark and the jaguar: Adventures in the simple and the complex. London: Abacus.

Granat, H. (2003). Wisdom through the ages: Book two. Bloomington: Trafford Publishing.

Groesser, S. N. (2014). Co-evolution of legal and voluntary standards: Development of energy efficiency in Swiss residential building codes. Technological Forecasting and Social Change, 87(1), 1-16. 
Groesser, S. N. (2015). Lab or reality: Entwicklung und Anylse von Geschäftsmodellen durch das kybernetische Unternehmensmodell Blue Company. In Exploring Cybernetics: Kybernetik im interdisziplinären Diskurs (pp. 91-116). Berlin: Springer.

Groesser, S. N. (2015). Stichwort: Dynamische Komplexität. Gabler Wirtschaftslexikon. Heidelberg: Gabler.

Groesser, S. N. (2015). Stichwort: System dynamics. Gabler Wirtschaftslexikon.

Groesser, S. N. (2016). Qualitative modellierung mit system dynamics. North Charleston: CreateSpace Independent Publishing Platform.

Groesser, S. N., \& Schaffernicht, M. (2012). Mental models of dynamic systems: Taking stock and looking ahead. System Dynamics Review, 28(1), 46-68.

Groesser, S. N., \& Schwaninger, M. (2012). Contributions to model validation: Hierarchy, process, and cessation. System Dynamics Review, 28(2), 157-181.

Holbrook, M. B. (2003). Adventures in complexity. Academy of Marketing Science Review, $6(1-18)$.

Isanda, M. (2014). Strategies for managing complexity. University of Nairobi.

Karakul, M., \& Qudrat-Ullah, H. (2008). How to improve dynamic decision making? Practice and promise. Complex decision making (pp. 3-24). Berlin: Springer.

Kastl, T., \& Schmid, A. (2008). Projektmanagement aus dem Blickwinkel von Komplexitäts- und Netzwerktheorie. Advanced Project Management. Herausforderungen - Praxiserfahrung Perspektiven. (pp. 213-232). Berlin: LIT.

Kersten, W., \& Lammers, T., et al. (2012). Schlussbericht zum Projekt "Komplexitätsanalyse von Distributionssystemen". Institut für Logistik und Unternehmensführung an der Technischen Universität Hamburg-Harburg.

Kirchhof, R. (2003). Ganzheitliches Komplexitätsmanagement - Grundlagen und Methodik des Umgangs mit Komplexität im Unternehmen. Wiesbaden: DUV.

Klabunde, S. (2003). Wissensmanagement in der integrierten Produkt- und Prozessgestaltung: Best-Practice-Modelle zum Management von Meta-Wissen. Wiesbaden: DUV.

Kupers, R. (2000). What organizational leaders should know about the new science of complexity. Complexity, 6(1), 14-19.

Labro, E., \& Tuomela, T.-S. (2003). On bringing more action into management accounting research: Process considerations based on two constructive case studies. European Accounting Review, 12(3), 409-442.

Lane, D. C. (2008). The emergence and use of diagramming in system dynamics: A critical account. Systems Research and Behavioral Science, 25(1), 3-23.

Lane, D. C., \& Oliva, R. (1998). The greater whole: Towards a synthesis of system dynamics and soft systems methodology. European Journal of Operational Research, 107(1), 214-235.

Levy, D. (1994). Chaos theory and strategy-Theory, application, and managerial implications. Strategic Management Journal, 15, 167-178.

Lewin, A. Y. (1999). Application of complexity theory to organization science. Organization Science, $10(3), 215$.

Little, J. D. C. (1970). Models and managers: The concept of a decision calculus. Management Science, 16(8), 466-485.

Malik, F. (2008). Strategie des Managements komplexer Systeme. Ein Beitrag zur Management-Kybernetik evolutionärer Systeme. Bern: Haupt.

Miller, G. (1956). The magical number seven, plus or minus two: Some limits on our capacity for processing information. The Psychological Review, 63(1), 81-97.

Miller, J. H., \& Page, S. (2007). Complex adaptive systems: An introduction to computational models of social life. In S. A. Levin \& S. H. Strogatz (Eds.). Princeton Press.

Morecroft, J. D. W. (2007). Strategic modelling and business dynamics: A feedback systems approach. Chichester: Wiley.

Nistelrooij, L. P. J. V., \& Rouwette, E. A. J. A., et al. (2015). The eye of the beholder: A case example of changing clients' perspectives through involvement in the model validation process. Systems Research and Behavioral Science, 32(4), 437-449.

Pascale, R. T. (1999). Surfing the edge of chaos. MIT Sloan Management Review, 40(3), 83-95. 
Phelan, S. E. (2001). What is complexity science really? Emergence, 3(1), 120-136.

Qudrat-Ullah, H. (2014). Yes we can: Improving performance in dynamic tasks. Decision Support Systems, 61(2014), 22-33.

Rall, K., \& Dallhöfer, J. (2004). Komplexität indirekter PRozesse bei der Erstellung variantenreicher Produkte. Zum Wirtschaftichen Fabrikbetrieb, 11, 623-640.

Richardson, G. P., \& Pugh, A. L., III. (1981). Introduction to system dynamics modeling with DYNAMO. Cambridge: MA, Productivity Press.

Rodrigues, A., \& Bowers, J. (1996). The role of system dynamics in project management. International Journal of Project Management, 14(4), 213-220.

Rouwette, E. A. J. A., Korzilius, H., et al. (2011). Modeling as persuasion: The impact of group model building on attitudes and behavior. System Dynamics Review (Wiley), 27(1), 1-21.

Satell, G. (2013). Management has to change in an increasingly complex world. Business Insider.

Schaffernicht, M., \& Groesser, S. (2014). The SEXTANT software: A tool for automating the comparative analysis of mental models of dynamic systems. European Journal of Operational Research.

Schaffernicht, M., \& Groesser, S. N. (2011). A comprehensive method for comparing mental models of dynamic systems. European Journal of Operational Research, 210(1), 57-67.

Scherf, O. (2003). Komplexität aus systemischer Sicht. München: Difo-Druck.

Schoeneberg, K.-P. (2010). Komplexität - Eine Einführung in die Komplexitätsforschung und Auswirkungen auf das Management komplexer Projekte. Marktorientierte Problemlösungen im Innovationsmarketing. Wiesbaden: Gabler: $482 \mathrm{ff}$.

Schöneborn, F. (2003). Strategisches controlling mit system dynamics. Heidelberg: Physica-Verlag.

Schwaninger, M. (2009a). Intelligent organizations: Powerful models for systemic management. Berlin and Heidelberg: Springer Publishing.

Schwaninger, M. (2009b). System dynamics in the evolution of the systems approach. In R. Meyers (Ed.), Encyclopedia of complexity and system science. Berlin, London, Paris: Springer Publishing.

Schwaninger, M., \& Groesser, S. N. (2008). Model-based theory-building with system dynamics. Systems Research and Behavioral Science, 25(4), 447-465.

Schwaninger, M., \& Groesser, S. N. (2009). System dynamics modeling: Validation for quality assurance. In Encyclopedia of complexity and system science. London: Springer Publishing.

Schwaninger, M., \& Ríos, J. P. (2008). System dynamics and cybernetics: A synergetic pair. System Dynamics Review, 24(2), 145-174.

Senge, P. M. (1990). The fifth discipline: The art and practice of the learning organization. New York: Currency \& Doubleday.

Senge, P. M. (1996). The fifth discipline and the infrastructures of a learning organization. Pegasus Communications: Waltham, MA.

Simon, H. (1962). The architecture of complexity. American Philosophical Society, 106(6), 467-482.

Simon, H. A. (1997). Administrative behavior: A study of decision-making processes in administrative organizations. New York, London, Toronto, Sydney, Singapore: The Free Press.

Stacey, R. D. (1995). The science of complexity-An alternative perspective for strategic change processes. Strategic Management Journal, 16(6), 477-495.

Sterman, J. D. (1994). Learning in and about complex-systems. System Dynamics Review, 10(2-3), 291-330.

Sterman, J. D. (2000). Business dynamics: Systems thinking and modeling for a complex world. Boston: MA, McGraw-Hill.

Sterman, J. D. (2002). All models are wrong: Reflections on becoming a systems scientist. System Dynamics Review, 18(4), 501-531.

Sterman, J. D. (2010). Does formal system dynamics training improve people's understanding of accumulation? System Dynamics Review, 26(4), 316-334. 
Sterman, J. D., Oliva, R., et al. (2015). System dynamics perspectives and modeling opportunities for research in operations management. Journal of Operations Management, 39-40 (November), 1-5.

Straub, R. (2013). Why managers haven't embraced complexity. Harvard Business Review, 56(5).

Ulrich, H., \& Probst, G. (1991). Anleitung zum ganzheitlichen Denken: Ein Brevier für Führungskräfte. Bern: Paul Haupt Verlag.

Ulrich, P., \& Fluri, E. (1992). Management. Bern: Haupt.

Vennix, J. A. M. (1996). Group model building: Facilitating team learning using system dynamics. Chichester: Wiley.

Warren, K. (2008). Strategic management dynamics. Chichester, West Sussex, England: Wiley.

Open Access This chapter is licensed under the terms of the Creative Commons Attribution-NonCommercial 4.0 International License (http://creativecommons.org/licenses/by-nc/ 4.0/), which permits any noncommercial use, sharing, adaptation, distribution and reproduction in any medium or format, as long as you give appropriate credit to the original author(s) and the source, provide a link to the Creative Commons license and indicate if changes were made.

The images or other third party material in this chapter are included in the chapter's Creative Commons license, unless indicated otherwise in a credit line to the material. If material is not included in the chapter's Creative Commons license and your intended use is not permitted by statutory regulation or exceeds the permitted use, you will need to obtain permission directly from the copyright holder.

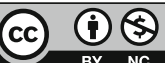

